IP Periodica Polytechnica Civil Engineering

\author{
59(2), pp. 155, 164,2015 \\ DOI: 10.3311/PPci.7144 \\ Creative Commons Attribution (1) \\ RESEARCH ARTICLE
}

\section{Mechanical and Durability Properties of Medium Strength Self-Compacting Concrete with High-Volume Fly Ash and Blended Aggregates}

\author{
Brabha $H$ Nagaratnam, Ahmed Faheem, Muhammad Ekhlasur Rahman, Mohammad \\ Abdul Mannan, Moussa Leblouba
}

Received 04-11-2013, revised 11-07-2014, accepted 26-11-2014

\begin{abstract}
This research investigates the fresh state properties and hardened state properties of medium strength, self-compacting concrete incorporating a high volume of class F fly ash as a partial replacement to cement and blended fine aggregates while maintaining satisfactory properties of SCC. The properties of self-compaction investigated are: slump flow, J-ring, L-box, Vfunnel, sieve stability and Visual Stability Index tests. Those of hardened concrete include compressive strength, splitting tensile strength, complete immersion water absorption, apparent volume of permeable voids, sorptivity, and rapid chloride ion penetration tests. The experiments on fresh state properties investigate the filling ability, the passing ability and the segregation resistance of concrete. The results show that fly ash improves workability and decreases the compressive strength as well as splitting tensile strength. Fly ash based SCC shows better resistance to water absorption, apparent volume of permeable voids, sorptivity, and chloride penetration than the control mix.
\end{abstract}

\section{Keywords}

Self-compacting concrete $(S C C) \cdot$ low calcium fly ash $\cdot$ fresh state properties $\cdot$ hardened state properties $\cdot$ blended fine aggregate

\section{Brabha H Nagaratnam}

Department of Civil and Construction Engineering, Curtin University Sarawak, CDT250 Miri, 98009, Malaysia

\section{Ahmed Faheem}

School of Civil Engineering, Engineering and Information Technologies, University of Sydney, NSW 2006, Australia, Australia

\section{Muhammad Ekhlasur Rahman}

Department of Civil and Construction Engineering, Curtin University Sarawak, CDT250 Miri, 98009, Malaysia

\section{Mohammad Abdul Mannan}

Department of Civil Engineering, Faculty of Engineering Universiti Malaysia Sarawak, 94300 Kota Samarahan, Sarawak, Malaysia

\section{Moussa Leblouba}

Department of Civil and Environmental Engineering, College of Engineering, University of Sharjah, P. O. Box 27272, Sharjah, United Arab Emirates

\section{Introduction}

Self-compacting concrete is a concrete that can be placed and compacted under its own weight without resorting to any compaction process while maintaining its homogeneity. This type of concrete can flow through and fill reinforcement gaps and formwork corners during placement. The elimination of compaction not only improves productivity (reduces the required labour by more than $50 \%$ and increases the construction speed) but is also a more sustainable approach [1]. It is used in the precast concrete industry and also in situ application. The main hypothesis for SCC is the reduction of coarse aggregate volume, incorporating a viscosity-enhancing admixture, or by reducing the waterto-cement ratio $(\mathrm{w} / \mathrm{c})$. This provides excellent deformability and adequate viscosity of the materials [2].

According to Sambasivan and Soon [3], one of the most obvious causes for delays in the Malaysian construction is low productivity and a shortage of skilled workers. A significant portion of the labour force in the construction industry comes from neighbouring countries and the majority of these labourers are unskilled. With the introduction of medium strength SCC the number of skilled workers required can be substantially reduced.

Under the current situation in the Malaysian construction industry, the application of SCC would be an essential change in the industry. Some of the obvious advantages of using SCC in Malaysia would include the reduced number of skilled workers required, improved concrete performance, a reduction in the overall construction cost and higher productivity. There are also many environmental benefits from the application of SCC. These include reduced noise pollution, greater energy savings and a reduction of dust in the air due to the absence of vibration.

Today, SCC is being researched worldwide, with papers being presented at almost every concrete related conference. However, most of the research done is based on High Strength Concrete. Vilanova et al. [4] developed a database from 138 references belonging to publications between the years 1997 to 2008 . There was a total of 627 mix proportions obtained, but median of compressive strengths, for different mix proportions of SCC, is around 50-60 MPa. In a number of practical applications the concrete strength is higher than actually necessary. This has cost 
consequences. In Malaysia, and many other developing countries, for most applications a concrete strength class of C25 is sufficient. However, especially in the lower strengths class, it is more difficult to obtain a robust and reliable self-compacting concrete. This clearly indicates the need to develop medium strength SCC for normal everyday construction use in Malaysia.

This paper presents a study on the mechanical and durability properties of medium strength SCC (compressive strength of 25 to $40 \mathrm{MPa}$ ) with high volumes of fly ash and blended aggregates. Fresh and hardened tests of samples with low fly ash content from this research have already been reported elsewhere [5. 6]. Laboratory mix trials were done using local construction materials for commercial application. The fine aggregates used in the Malaysian construction market are of poor quality and do not meet the fineness or grading requirements of EN 12620:2013 [7] or ASTM C33 [8]. In order to accommodate to this lack of quality, blended fine aggregates have been introduced. Results from the fresh and hardened tests were compared to results by other researchers.

\section{Materials}

\subsection{Cement}

The cement used in this research conforms to the requirements set under EN 197-1:2011 [9] Type I Ordinary Portland Cement. It is of grade 42.5 and the particle density is $2950 \mathrm{~kg} / \mathrm{m}^{3}$ and the chemical composition is given in Table 1.

\subsection{Fly Ash}

Low calcium fly ash, Class F as per ASTM C618 [10], was obtained from the Sejingkat Coal-Fired Power Station in Sejingkat, Kuching. The coal used in this power station was mainly supplied from the coal mine in Merit Pila, Kapit, Sarawak, Malaysia. The chemical composition of the fly ash, as determined by X-Ray Fluorescence (XRF) analysis is given in Table 1.

Tab. 1. Chemical Composition of Fly Ash and Cement

\begin{tabular}{ccc}
\hline Compound & Fly ash & Cement \\
\hline $\mathrm{SiO}_{2}$ & 57.8 & 20.0 \\
\hline $\mathrm{Al}_{2} \mathrm{O}_{3}$ & 20.0 & 5.20 \\
\hline $\mathrm{Fe}_{2} \mathrm{O}_{3}$ & 11.7 & 3.30 \\
\hline $\mathrm{SO}_{3}$ & 0.08 & 2.40 \\
\hline $\mathrm{MgO}$ & 1.95 & 0.80 \\
\hline $\mathrm{CaO}$ & 3.28 & 63.2 \\
\hline $\mathrm{K}_{2} \mathrm{O}$ & 3.88 & - \\
\hline $\mathrm{TiO}_{2}$ & 2.02 & - \\
\hline $\mathrm{Na}_{2} \mathrm{O}$ & 0.30 & - \\
\hline $\mathrm{SO}_{3}$ & & 2.40 \\
\hline Loss on ignition & 0.32 & 2.50 \\
\hline
\end{tabular}

\subsection{Coarse Aggregate}

Coarse aggregates are composed of crushed quartzite particles within the range of $5 \mathrm{~mm}$ to $10 \mathrm{~mm}$. The aggregates gra- dation in Table 2 shows that the entire sample passed through $9.5 \mathrm{~mm}$ sieve while only $5 \%$ passed the $4.75 \mathrm{~mm}$ sieve. The sample is a single sized aggregate.

Tab. 2. Coarse Aggregate Gradation

\begin{tabular}{ccc}
\hline Sieve Size $(\mathrm{mm})$ & Finer than sieve $(\%)$ & EN requirements $(\%)$ \\
\hline 9.5 & 100 & $85-100$ \\
\hline 4.75 & 5 & $10-30$ \\
\hline 2.36 & 0 & $0-10$ \\
\hline
\end{tabular}

\subsection{Fine Aggregate}

The fine aggregates consist of locally available aggregates with a maximum size of $5 \mathrm{~mm}$. Two categories of fine aggregate were chosen after various bulk density tests. The first type (FA Type 1) is crushed quartzite that has a size range of 600 $\mu \mathrm{m}$ to $5.0 \mathrm{~mm}$ as per Table 3 . The other category (FA Type 2) is uncrushed river sand and has a nominal size of $600 \mu \mathrm{m}$ and a small amount of fines with particle size of less than $75 \mu \mathrm{m}$ (see Table 4 for aggregate gradation). Physical properties of the fine aggregates are given in Table 5. The fineness modulus for fine aggregates in this region is around 1.3 where in most other places are 2.5 and above. This demonstrates the relevance of using the coarser crushed quartzite in the mix.

Tab. 3. Fine Aggregate Type 1 (Crushed Quartzite) Gradation

\begin{tabular}{lcc}
\hline Sieve Size & Finer (\%) & ASTM requirements for fine aggregates (\%) \\
\hline $4.75 \mathrm{~mm}$ & 99 & $95-100$ \\
\hline $2.36 \mathrm{~mm}$ & 50 & $80-100$ \\
\hline $1.18 \mathrm{~mm}$ & 20 & $50-85$ \\
\hline $600 \mu \mathrm{m}$ & 2 & $25-60$ \\
\hline
\end{tabular}

Tab. 4. Fine Aggregate Type 2 (River Sand) Gradation

\begin{tabular}{ccc}
\hline Sieve Size & Finer (\%) & ASTM requirements for fine aggregates (\%) \\
\hline $600 \mu \mathrm{m}$ & 100 & $25-60$ \\
\hline $300 \mu \mathrm{m}$ & 58 & $5-30$ \\
\hline $150 \mu \mathrm{m}$ & 10 & $0-10$ \\
\hline
\end{tabular}

\subsection{Superplasticizer}

A high range water reducer was used in this research The super-plasticiser was of Naphthalene Formaldehyde Sulphonate type and conforms to the requirements of EN 934-2 [11].

\section{Mix Proportions and Procedure}

The mix proportions are reported in Table 6. The binder content was kept constant at $540 \mathrm{~kg} / \mathrm{m}^{3}$ and the fly ash replacement ratio varied from 40 to $70 \%$ at a $10 \%$ interval. For all mixes the water to binder ratio was kept constant at 0.38 or 0.39 . The coarse aggregate and FA Type 1 were kept constant at 690 and $630 \mathrm{~kg} / \mathrm{m}^{3}$ respectively. FA Type 2 was varied from 220 to $240 \mathrm{~kg} / \mathrm{m}^{3}$. 
Tab. 5. Aggregate Characteristics Summary

\begin{tabular}{|c|c|c|c|c|c|c|}
\hline & Material Type & Size Range & $\begin{array}{l}\text { Fineness } \\
\text { Modulus }\end{array}$ & $\begin{array}{c}\text { Water } \\
\text { Absorption }\end{array}$ & Specific Gravity & Sample \\
\hline \multirow[t]{2}{*}{ Fine Aggregate } & $\begin{array}{l}\text { Crushed } \\
\text { Quartzite }\end{array}$ & $\begin{array}{c}600 \mu \mathrm{m} \text { to } \\
5 \mathrm{~mm}\end{array}$ & 4.29 & $1.30 \%$ & 2.67 & \\
\hline & $\begin{array}{l}\text { Uncrushed } \\
\text { River Sand }\end{array}$ & $0 \mu \mathrm{m}$ to $600 \mu \mathrm{m}$ & 1.32 & $1.10 \%$ & 2.64 & \\
\hline $\begin{array}{c}\text { Coarse } \\
\text { Aggregate }\end{array}$ & $\begin{array}{l}\text { Crushed } \\
\text { Quartzite }\end{array}$ & $5 \mathrm{~mm}$ to $10 \mathrm{~mm}$ & & $1.40 \%$ & 2.62 & \\
\hline
\end{tabular}

All concrete mixes were prepared in a pan mixer. Sand and aggregates were homogenised for one minute, followed by the addition of cement mix with fly ash for another one minute. $60 \%$ of the required water was added slowly and the mixer ran for 1 to 1.5 minutes. $30 \%$ of the water and $90 \%$ of the super-plasticiser was mixed in a bucket, then slowly added to the pan and run for about 3 to 3.5 minutes. The consistency and the flow of the resulting mixes were observed and the remaining $10 \%$ of water and $10 \%$ of the super-plasticiser (mixed together) were added to the mix. The resulting mixture was then allowed to rest for 3 minutes, and then remixed for 20 to 30 seconds before conducting the fresh state tests.

\subsection{Tests on Fresh State Properties}

Immediately after the mixing was completed, the fresh concrete was sampled and tested for filling ability, passing ability, and segregation resistance. Standard procedures [12-15] were used to test these requirements. Slump flow and V-funnel tests were used to measure the filling ability. Slump flow measures the maximum uninterrupted flow width of SCC through a slump cone. The maximum spread and time to reach a $500 \mathrm{~mm}$ diameter circle $\left(T_{500 s}\right)$ were noted. The V-funnel flow tests were carried out according to the procedures given by European guidelines [12,13]. $V_{10} s$ and $V_{15} \min$ are the time parameters required for a mass of concrete to completely flow though the trap door of the funnel in $10 \mathrm{~s}$ and $15 \mathrm{~min}$ respectively.

Passing ability was tested using J-ring and L-box tests. J-ring measures the blockage of concrete due to the presence of reinforcement bars and is carried out by first holding a mass of concrete in a 'slump cone', placing the J-ring and then lifting the cone, thus allowing concrete to pass through the reinforcement. The time taken by concrete to reach a $500 \mathrm{~mm}$ diameter circle from the centre $\left(T_{500 j}\right)$, the maximum spread and the average concrete height difference between the centre and outside of the ring (blocking step) were measured. As for the L-box test, concrete was poured into the vertical section of the 'box', allowing it to pass through the bar spaces into the horizontal section. The ratio of the height in the vertical section (H1) to the end of the horizontal section (H2) was noted as the passing ratio; this measures the SCC's viscosity and flow-ability.
Segregation resistance was measured through a sieve segregation test. A mass of SCC was allowed to pass through a sieve with an aperture of $4.75 \mathrm{~mm}$ for 2 minutes. Weight of the sieved portion was then expressed as a percentage of the total weight of SCC used in the test. A visual segregation rating was also given [14] for each mix after observing the nature of the spread during a slump flow test.

\subsection{Tests on hardened state of SCC for strength}

Cylindrical specimens casted were tested for compressive and tensile strengths using a Universal Testing Machine, as per EN 12390-3 [16] and EN 12390-6 [17] respectively. Compression tests were carried out after $3,7,14,28,56$, and 84 days of curing while splitting tests were carried out after 14, 28, 56, and 84 days.

\subsection{Tests on hardened state SCC for durability}

As per standard requirements, initially casted $200 \mathrm{~mm}$ long cylinders were sliced into four pieces of $50 \mathrm{~mm}$ long each for durability tests. All tests were carried out at 14, 28, 56, and 84 days, after curing, except for a rapid chloride ion penetration test, which was carried out only at 28 and 84 days.

Complete immersion water absorption was measured by first noting the oven dry weight, then immersing in water for 48 hours, and finally calculating the weight gain as a percentage of the oven dry weight. For the apparent volume of permeable voids or boiled permeability tests, samples were oven dried (noting dry mass as MO), then boiled in water for 5 hours, eventually left to cool down for 14 hours (surface dry mass as MSD) and finally the specimens were weighed while suspended in water (MA). The expression 100×(MSD-MO)/(MSD-MA) was used to calculate apparent volume of permeable voids. These tests were done according to ASTM 642-13 [18].

A sorptivity test measures the capillary suction of concrete when it comes into contact with water. The test was done according to ASTM C1585-13 [19]. Samples were oven dried until they reached a constant weight and were then put in contact with water on one surface while sealing the other surfaces. Mass gain due to sorption was measured at definite intervals and the rate of sorption is calculated as the slope of the best-fit line to 
Tab. 6. Mix Proportions

\begin{tabular}{|c|c|c|c|c|c|}
\hline Mix no. & $\mathrm{FAO}$ & FA40 & FA50 & FA60 & FA70 \\
\hline $\begin{array}{c}\text { Water to } \\
\text { powder ratio }\end{array}$ & 0.38 & 0.39 & 0.38 & 0.38 & 0.39 \\
\hline $\begin{array}{c}\text { Cement by } \\
\text { weight of } \\
\text { powder }\left(\mathrm{kg} / \mathrm{m}^{3}\right)\end{array}$ & 540 & 324 & 270 & 216 & 162 \\
\hline $\begin{array}{c}\text { Fly ash by } \\
\text { weight of } \\
\text { powder }\left(\mathrm{kg} / \mathrm{m}^{3}\right)\end{array}$ & 0 & 216 & 270 & 324 & 378 \\
\hline $\begin{array}{l}\text { FA type } 1 \\
\left(\mathrm{~kg} / \mathrm{m}^{3}\right)\end{array}$ & 630 & 630 & 630 & 630 & 630 \\
\hline $\begin{array}{c}\text { FA type } 2 \\
\left(\mathrm{~kg} / \mathrm{m}^{3}\right)\end{array}$ & 230 & 240 & 230 & 230 & 220 \\
\hline $\begin{array}{c}\text { Coarse } \\
\text { aggregate } \\
5 / 10 \mathrm{~mm} \\
\left(\mathrm{~kg} / \mathrm{m}^{3}\right)\end{array}$ & 690 & 690 & 690 & 690 & 690 \\
\hline $\begin{array}{c}\text { Superplasticiser } \\
\text { (\% by powder } \\
\text { weight) }\end{array}$ & $1.80 \%$ & $1.65 \%$ & $1.65 \%$ & $1.60 \%$ & $1.60 \%$ \\
\hline $\begin{array}{c}\text { Concrete } \\
\text { Density }\left(\mathrm{kg} / \mathrm{m}^{3}\right)\end{array}$ & 2305 & 2320 & 2304 & 2298 & 2288 \\
\hline
\end{tabular}

the plot of absorption versus the square root of time at which uptake was recorded.

Rapid chloride penetration test [20] were carried out by coating curved surfaces with silicone in a vacuum desiccator for 3 hours and then measuring a current of $60 \mathrm{~V}$ passing though the specimen for 6 hours. The chloride penetration of the sample was expressed as the total charge passed in Coulomb during the test period.

\section{Results and discussion}

\subsection{Fresh SCC properties}

\subsubsection{Filling Ability}

Table 7 shows the impact of fly ash on the fresh properties of SCC. The slump flow of the SCC was in the range of 630 $715 \mathrm{~mm}$ and the flow time $\left(\mathrm{T}_{500 \mathrm{~s}}\right)$ was in the range of $2-3 \mathrm{~s}$. This was within the range of $550-850 \mathrm{~mm}$ and $2-5 \mathrm{~s}$ specified by the European guidelines for self-compacting concrete [13] as the slump and flow-time required for concrete to be selfcompacted.

As observed by Bouzabaa and Lachemi [21] and Pathak and Siddique [22], SP could be decreased marginally while maintaining water to powder ratio (w/p) at constant values. At 50\% fly ash, SP and fine aggregate (FA) type 2 was decreased to improve flow. Since fines demand more water, the decrease in fines allows the usage of water and SP for flow improvement rather than for excessive paste production [23]. FA type 2 was further decreased for FA70 leading to an even larger spread at $715 \mathrm{~mm}$. In a similar test (the replacement of $33-75 \%$ by weight), Liu [24] reported a slump flow of $705-730 \mathrm{~mm}$. The slight variation could be due to the angularity of aggregates used in the research as aggregates in this region are relatively coarser. Benabed et al.
[25] reported that aggregates with low fineness require high water demand and a larger amount of cement in relation to crushed or river sand in order to achieve high fluidity.

Table 7 shows that $\mathrm{V}$-funnel time, $V_{10} s$ and $V_{15 \min }$ were in the range of 3- 6 sand 7-8.2 s respectively. The $V_{10} s$ flow time $(\leq 8 \mathrm{~s})$ indicates that the plastic viscosity of concrete was comparatively low [12] and implies a faster filling rate. Liu [24] also reported similar observations on V-funnel flow time. These results indicate an improvement in filling ability with an increase in fly ash content. The capacity that fly ash has to increase workability can be explained in terms of the spherical and smooth nature of the particles that aid in the reduction of friction between particles during flow, known as the ball bearing effect.

\subsubsection{Passing Ability}

The maximum spread in J-ring $\left(T_{500 \mathrm{~J}}\right)$ varies in the range of $510-610 \mathrm{~mm}$ and the $T_{500 \mathrm{~J}}$ time are relatively constant at 6 or $7 \mathrm{~s}$ (Table 7). Blocking step varied in the range of $4-5.3 \mathrm{~mm}$ for all sand samples at above $50 \%$ replacement and there is no significant difference in the spread or blocking step values. According to EFNARC [12], a blocking step of $0-10 \mathrm{~mm}$ forms the acceptable criteria for SCC. Liu [24] also reported similar values for the spread and $T_{500 \mathrm{~J}}$ time. However, the blocking step is much higher $(15-23 \mathrm{~mm})$ in her research, as the maximum aggregate size used is larger. This demonstrates how a smaller aggregate size ensures a more reliable SCC mix.

The L-box ratio for the control mix is 0.6 whereas it is around 0.9 for all other mixes. The EGSCC [13] specifies a value of 0.8 - 1.0 for L-box ratio. The higher passing ratio indicates better passing ability of the mix and it is evident that the incorporation of fly ash into SCC has a positive effect on passing ability. The 
constant values are caused by the variation in SP and FA type 2 content. It can be concluded that the passing ratios improve with an increase in fly ash content.

\subsection{Segregation Resistance}

The VSI values for the concrete were almost similar for all samples at 1.0 or 1.5. The concrete mixture with a VSI of 1.5 showed only slight bleeding and a very slight ring around the paste. The segregation test was more accurate with the sieve tests. The sieved portions for all mixes in this study are in the range of $7.8-9.2 \%$ (Table 7 ). The lower percentage of segregation indicates a higher resistance to segregation. A value below $5 \%$, in general, implies that it might obstruct flow, while segregation beyond $30 \%$ would lead to segregation of the entire sample. Furthermore, EGSCC [13] categorises mixes with sieved portion less than $15 \%$ under class 2 , which means that the concrete is satisfactory for even vertical applications. This accomplishment is explainable in terms of the high powder content (total of $540 \mathrm{~kg} / \mathrm{m}^{3}$ ) in the mixes. High paste content generally leads to high resistance to segregation as the paste 'holds' the aggregates in place. An increase in the fly ash content in the mix increases the sieved portion thus decreasing the resistance against segregation. This trend correlates with that previously reported by Sonebi [26]. On the contrary, Liu [24] reported a significant decrease in sieved portions at higher levels of fly ash. This contradiction can be explained by difference in SP and fine aggregate content. In this research, the SP dosage was increased slightly beyond FA40 while fine aggregate content was decreased. This led to a more 'fluid' mix. Liu [24] kept fine aggregates constant while decreasing SP dosage, thus leading to a more resistant mix.

\subsection{Compressive Strength}

The compressive strengths of SCC samples at different ages are illustrated in Fig. 1 and summarised in Table 8 . With the development in time from 3 to 84 days, SCC mixes developed compressive strengths from 28.2 to $58.2,16$ to $38.1,10.4$ to 33,9 to 28.5 , and 4.6 to $16.6 \mathrm{MPa}$ for FA 0, FA 40, FA 50, FA 60, and FA 70 respectively. It is shown that the compressive strengths decreased with the increase in fly ash content and this has been observed by other researchers [21, 29]. The loss in strength with the increase in fly ash content is mainly due to the low calcium content of class $\mathrm{F}$ fly ash that slows down the cementing process.

It can also be seen that, for all mixes, the biggest strength gain occurs between 3 and 14 days. These results agree with the general strength development curves for concrete, published by Warner et al. [31]. The steepest strength gain for the control mix demonstrates that the strength gain for these samples is faster than the fly ash containing mixes at early stages, as the low amount of cement fails to produce sufficient hydration of the paste. Within the period of 14 to 28 days, all the mixes containing fly ash show higher strength gains compared to the control mix with the highest gain observed for FA 70. This shows that

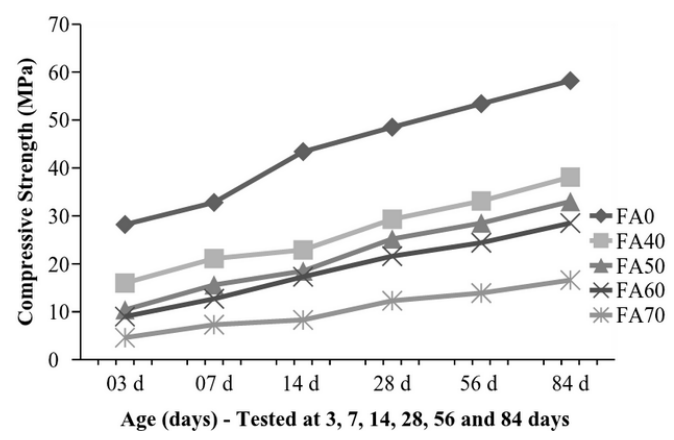

Fig. 1. Compressive strength gain with time

the percentage of strength gain is synchronous with the increase in fly ash content in the mix. In the long term, slopes for fly ash containing mixes steepen, thus gaining strength faster as fly ash undergoes pozzolanic reactions beyond 28 days. It can also be seen that at higher cement replacement levels, the strength is less significant. For instance at 3 days, the strength of FA 70 is almost six times lower than that of FA0 but at 84 days it is only about three times higher. This decrement of gap, between the control mix and the fly ash containing mixes in the long term, was also observed by both Liu [24] and Khatib [27].

All mixes that have 28 day strengths within the range of $25 \mathrm{MPa}$ to $40 \mathrm{MPa}$ are hence categorised as medium-strength SCC. Those that fall under this strength range are FA 40 and FA 50. The compressive strength of FA 60 is $21.6 \mathrm{MPa}$ is still acceptable for common use although it falls outside the reference range for this research. FA 70 reaches $12.3 \mathrm{MPa}$ at 28 days and is therefore not acceptable for the construction of primary structural elements. It should be noted that Liu [24] and Khatib [27] obtained much higher strengths at corresponding cement replacement levels because their mixes contained lower water to cement ratios along with aggregates of higher fineness. Hence even at a $40 \%$ replacement level, they observed strengths greater than $50 \mathrm{MPa}$. Benabed et al. [25] reported that strength of mortar with binary or ternary sands was superior to that of mortar made with only crushed sand at all ages. This decrease in strength is attributed to an increase in surface area of the fine aggregates (requiring more cement to coat the surfaceof the aggregates).

\subsubsection{Tensile Strength}

Fig. 2 shows that the tensile strength decreases with the increase in fly ash content. As was observed for compressive strength results, the steepest rise is seen for the control mix prior to 14 days whereas, for other mixes, the slope becomes less steep with increasing fly ash content. After 28 days, the strength development is almost linear for all mixes. The slope for FA0 is the least steep while all mixes containing fly ash show similar slopes. With tensile strength, gain is more intensive compared to compressive strength. This is due to fly ash reactions which improve interfacial bonds holding concrete together. If particles are held loosely, the 'pulling effect' imposed on specimens during tensile loading could easily lead to failure. 
Tab. 7. Fresh State Properties of SCC

\begin{tabular}{|c|c|c|c|c|c|c|}
\hline \multicolumn{2}{|c|}{ Fresh state properties } & \multirow{2}{*}{$\begin{array}{c}\text { FAO } \\
7\end{array}$} & \multirow{2}{*}{$\begin{array}{c}\text { FA40 } \\
7\end{array}$} & \multirow{2}{*}{$\frac{\text { FA50 }}{7}$} & \multirow{2}{*}{$\begin{array}{c}\text { FA60 } \\
6\end{array}$} & \multirow{2}{*}{$\frac{\text { FA70 }}{6}$} \\
\hline & $T_{500 \mathrm{~J}}(\mathrm{sec})$ & & & & & \\
\hline \multirow[t]{2}{*}{$\mathrm{J}$-ring test } & Spread (mm) & 510 & 530 & 590 & 610 & 610 \\
\hline & $\begin{array}{l}\text { Blocking } \\
\text { Step (mm) }\end{array}$ & 5.2 & 5.3 & 4.0 & 4.1 & 4.0 \\
\hline L-box test & $\begin{array}{c}\text { Passing ratio } \\
(\mathrm{H} 1 / \mathrm{H} 2)\end{array}$ & 0.6 & 0.8 & 0.9 & 0.8 & 0.9 \\
\hline \multirow{2}{*}{ V-funnel test } & $\mathrm{V}-10 \mathrm{~s}(\mathrm{sec})$ & 5.9 & 5.1 & 4.9 & 4.8 & 3.9 \\
\hline & $\begin{array}{c}\text { V-15min } \\
\text { (sec) }\end{array}$ & 8.2 & 7.3 & 7.3 & 7.1 & 7.0 \\
\hline \multirow{2}{*}{ Slump flow } & $T_{500 \mathrm{~S}}(\mathrm{sec})$ & 3 & 2.5 & 2 & 2 & 2 \\
\hline & Spread $(\mathrm{mm})$ & 630 & 680 & 695 & 700 & 715 \\
\hline $\begin{array}{c}\text { Sieve } \\
\text { stability test }\end{array}$ & $\begin{array}{c}\text { Sieved } \\
\text { Potion (\%) }\end{array}$ & 8.2 & 7.8 & 8.6 & 9.1 & 9.2 \\
\hline $\begin{array}{c}\text { Visial } \\
\text { stability } \\
\text { indexing }\end{array}$ & $\begin{array}{c}\text { Visial } \\
\text { Stability } \\
\text { Index }\end{array}$ & 1.0 & 1.5 & 1.0 & 1.5 & 1.5 \\
\hline
\end{tabular}

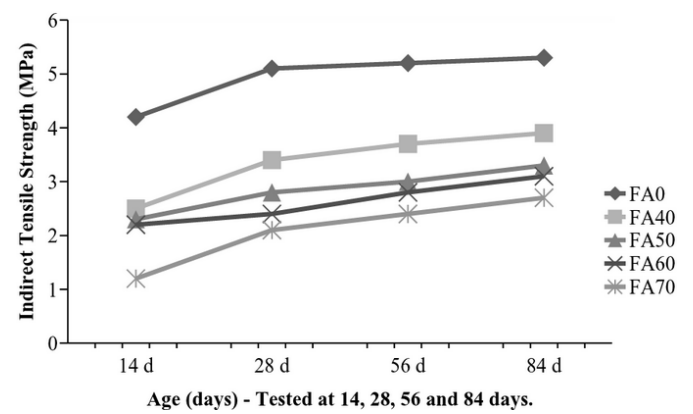

Fig. 2. Indirect tensile strength gain with time

\subsubsection{Relations between compressive strength and tensile strength}

The 28 day's splitting tensile strengths are around $11 \%$ of the corresponding compressive strengths for all the samples except FA 70. Generally, the splitting tensile strength for normal vibrated concrete is $8-14 \%$ of the compressive strength [32]. With reference to Fig. 3, as the compressive strength increases, the splitting tensile strength also increases albeit at a decreasing rate. This trend was also reported by Neville [33]. The datafitting analysis, based on the results of the present study, provided a parabolic relationship between the compressive strength and the splitting tensile strength and is given by Eq. (1):

$$
f_{c m}=6.18 f_{c t m}^{1.4171}
$$

where $f_{c m}$ is the mean compressive strength in $\mathrm{MPa}$ and $f_{c t m}$ is the mean tensile strength in MPa.

Fig. 3 also shows the comparison of the experimental values of compressive strength and splitting tensile strength in this research, compared with Liu [24] and Sukumar [29]. It shows that most splitting tensile strength values of SCC are in the range of the CEB - FIB Model Code 90 for normal vibrated concrete with the same compressive strength. Liu's results (Eq. (2)) are for SCC with similar cement content $\left(540 \mathrm{~kg} / \mathrm{m}^{3}\right)$ and maximum aggregate size of $20 \mathrm{~mm}$ whereas Sukumar's results (Eq. (3))

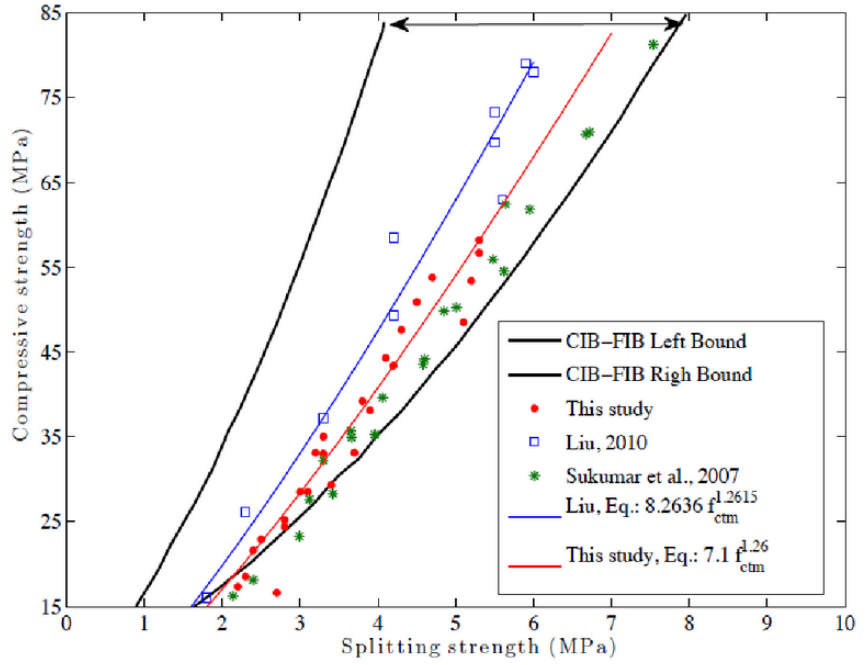

Fig. 3. Compressive strength vs splitting tensile strength of SCC with fly ash and blended aggregate in comparison with SCC with only fly ash.

are for maximum aggregate size of $12 \mathrm{~mm}$ and SCC grade 30 to $70 \mathrm{MPa}$. Both experiments predict the splitting tensile strengths from the cube compressive strengths. The values in Fig. 3 are independent of both fly ash content and the curing age of samples.

$$
f_{c m}=8.2636 f_{c t m}^{1.26}
$$

$f_{c t m}=0.0843 f_{c m}+0.818$ or $f_{c m}=11.8624 f_{c t m}-9.70344$

It can be seen that there are some splitting tensile strengths that are higher than the CEB - FIB Model Code 90 range. This is because of a better microstructure and denser paste matrix, due to the addition of powder [34]. 


\subsection{Durability of Hardened SCC}

\subsubsection{Immersed water abosorption}

Immersed water absorption indicates the amount of water absorbed by the material when immersed in water for a stipulated period of time. The influence of varying fly ash on immersed water absorption is shown in Fig. 4. There is a decrease in absorption with an increase in the curing period and this decrease is substantial from 28 to 56 days for SCC with high volumes of fly ash. The highest absorption level (7\%) is after 14 days of the curing period with no significant difference between samples. This is because concrete matrix is porous at early ages. Beyond 14 days, cement replacement with up to $70 \%$ fly ash improves water absorption substantially. This improvement is due to the reaction rate of fly ash over time as high proportions of fly ash fill inter-particle voids in the concrete matrix, creating finer pore structure which then reduces absorption. However, Dinakar et al. [35] reported that, in fresh state, normal vibrated concrete has higher water absorption than SCC with fly ash due the relatively lower paste volume, i.e. smaller capillary pore volume.

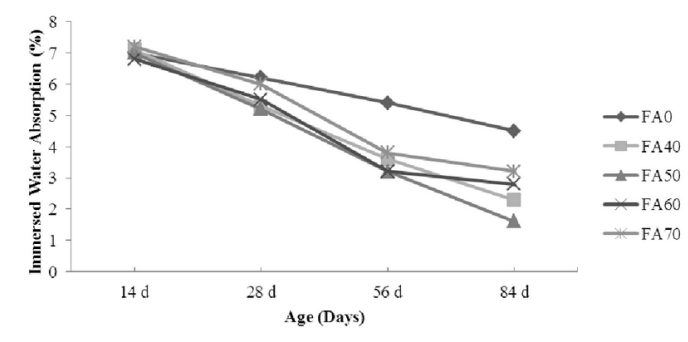

Fig. 4. Immersed water absorption gain with time

\subsubsection{Apparent volume of permeable voids}

Fig. 5 shows that the variation of apparent volume of permeable voids with fly ash is similar to the water absorption rate. Boiling reduces the ability of fly ash to resist water intake. Thus, for the same fly ash content, boiled permeability is higher than water absorption. apparent volume of permeable voids values for all samples were less than $12 \%$. Kao [36] reported an absorption rate of more than $12 \%$ for normal vibrated concrete containing fly ash. This proves that SCC in general is more durable than normal vibrated concrete. There is not any significant difference between absorption rates; around $11 \%$ at 14 days and $8 \%$ for all samples at 28 days. However at 56 days, there is a noticeable difference in the absorption rate between the control mix and fly ash containing mixes. This is even more obvious at 84 days as FA 40 has an absorption rate of half that of the control mix. It is worth noting that the apparent volume of permeable voids and the water absorption rate start increasing again beyond $40 \%$ and $50 \%$ replacement. The absorption rate for all samples is much lower than the acceptable limit proposed by most guidelines (less than $11 \%$ ), due to the high paste content. Incorporation of low calcium fly ash in the mixes aided in further improvement, especially at late stages (dropped to only $3.0 \%$ at 84 days for FA 40).

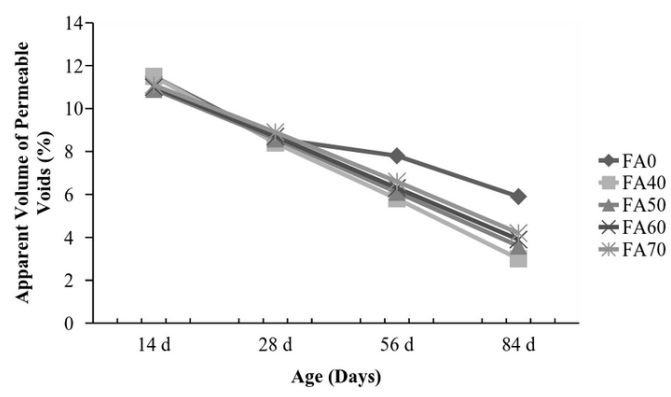

Fig. 5. Apparent volume of permeable voids with time

\subsubsection{Sorptivity}

Table 8 and Fig. 6 show that the sorptivity coefficient decreases over time. Smaller values indicate a better resistance to absorption. The decreasing trend starts at 14 days, unlike immersed water absorption and apparent volume of permeable voids tests. This could occur because the samples are in contact with water on only one surface, thus making capillary suction the most dominant water uptake mechanism. At 14 days, sorptivity coefficient of FA 70 is 1.51 which is 2 times greater than the control mix and at 84 days this value reduces to 0.49 and is only 1.3 times greater than the control mix. This is similar to some results on normal vibrated concrete [37]. The high absorption values at 14 days are due to the low amount of hydration product produced, thus leading to poor microstructure within the concrete matrix. With an increasing curing duration, more hydration occurs making the pore structure denser. This blocks most of the interconnections between the capillary pores within the concrete matrix which leads to a significant decrement in capillary paths for water uptake, hence lowering the sorption coefficients. The optimum fly ash content for sorptivity is $40 \%$ as reported by Liu [24].

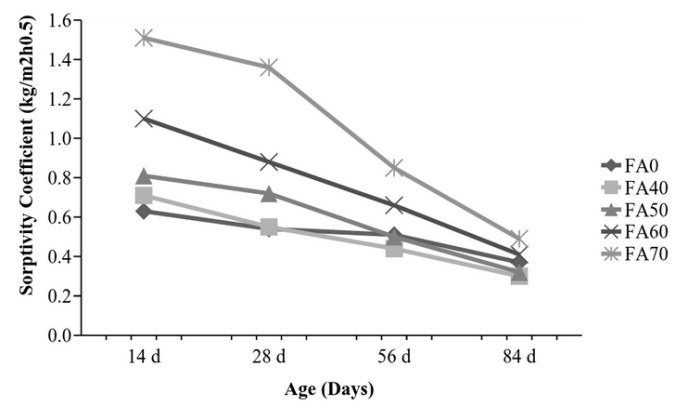

Fig. 6. Sorptivity with time

Fig. 7 shows that there is a good correlation between compressive strength and sorptivity. The higher the compressive strength is, the lower the permeability. This is compared with Liu's study for sorptivity compressive strength at 7 and 90 days. From this research it can be seen that the sorptivity coefficient at 84 days, with similar compressive strengths, is similar to Liu's results for 90 days.

\subsubsection{Rapid chloride ion penetration}

It can be seen from Table 8 and Fig. 8 that all the fly ash containing mixes show better resistance to chloride penetration 


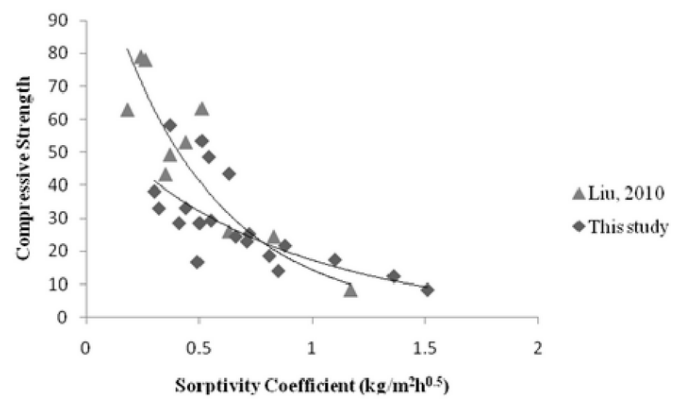

Fig. 7. Compressive strength with sorptivity

than the control mixture. The total charge values passed, Q (in Coulomb) at 84 days are 1350, 690, 780, 782, and 800 for FA 0 , FA 40, FA 50, FA 60, and FA 70, respectively. As per ASTM C1202 criteria, all the fly ash containing mixes in this study, at 84 days, fall under a 'very low' penetrability category $(\mathrm{Q}=100$ to 1000 Coulombs) while the control mix falls under the 'low' category ( $Q=1000$ to 2000 Coulombs). Naik et al. [38] reported that fly ash containing normal vibrated concrete showed 'low' penetrability at 3 months while the control mix with no fly ash fell under the 'moderate category'. It is apparent that SCC, in general, has better chloride resistance than normal vibrated concrete. In the case of normal vibrated concrete, even when vibration is carried out correctly, the resulting placement is not homogenous as different areas receive different amount of compaction effort or energy. This leaves different portions of the structure with different permeability which encourages the penetration of detrimental substances [39]. When the fly ash percentages were between $30 \%$ and $60 \%$, Patel et al. [40] reported a similar rapid chloride penetration range. Also, Siddique [30] reported a Coulomb charge of 594 to 662 at 90 days and a Coulomb charge of 303 to 381 at 360 days when the fly ash percentages were between 15 to $35 \%$. A correctly proportioned SCC will create structures of consistently low and uniform permeability, leaving a minimal amount of weak areas for deteriorative substances to attack [41].

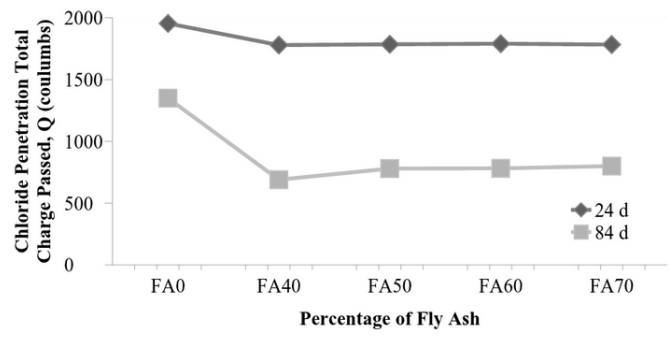

Fig. 8. Chloride penetration with time

It can also be seen that the decrease in $Q$ from 28 to 84 days, for the control mix, is the least of all the mixes (i.e. 1954 $1350=600$ ). This means the long term penetrability of chloride ion is lower for mixes containing fly ash. The fact that mixes containing fly ash show higher resistance against chloride penetration can be explained by the changes that fly ash brings to the concrete matrix. The pore structure of concrete is dependent on the hydration that occurs. The incorporation of fly ash aids in the densification of the internal pore structure and reduces the pore volume, which in turns resists chloride ion passage. Chloride penetration is highly dependent on the permeability of the mix as can be seen from Fig.9 and Fig. 10, where apparent volume of permeable voids and immersed water absorption correlates with the total current charge that passes through the sample. The following equations are proposed for determining the total current charge passing through a sample, $Q$ in Coulombs

$$
\begin{aligned}
& Q=381.03 P^{0.8667} \quad\left(R^{2}=95\right) \\
& Q=216.74 P_{a}^{0.9863}\left(R^{2}=95\right)
\end{aligned}
$$

where $P$ is the percentage of immersed water absorption and $P_{a}$ is the percentage of apparent volume of permeable voids. Both results give an accuracy of $95 \%\left(R^{2}\right)$ thus indicates a good correlation between permeability and chloride penetration.

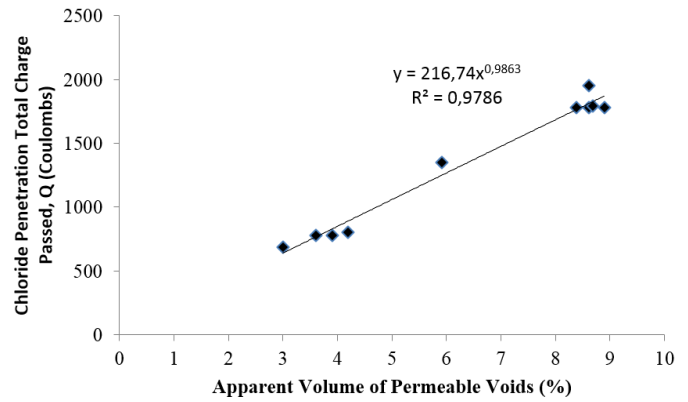

Fig. 9. Apparent volume of permeable voids vs. chloride penetration

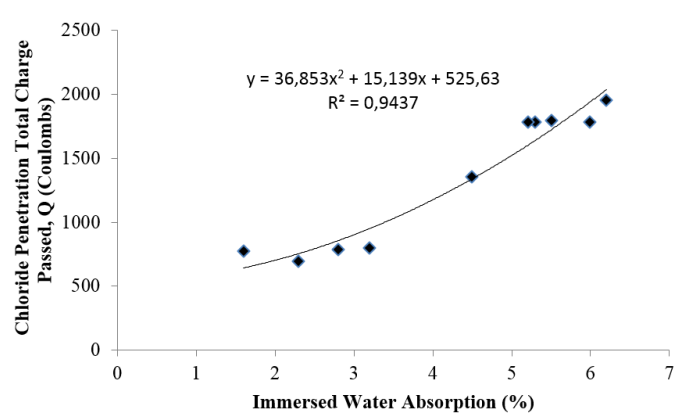

Fig. 10. Immersed Water Absorption vs. Chloride Penetration

\subsubsection{Materials and Carbon Footprint}

Besides energy consumption, significant amounts of virgin materials, including limestone and clay, are consumed to produce cement. 1.5 tonnes of virgin materials are needed to produce one ton of cement [42]. Cement production industries are accountable for more or less $7 \%$ of the world's carbon dioxide discharge and to produce 1 tonne of cement approximately 1 ton of $\mathrm{CO}_{2}$ is released into the atmosphere [42, 43]. Fly ash is a byproduct which can be found abundantly over a very large part of the world and is a contributor to air, river, sea and groundwater pollution. This study shows that fly ash has a good potential as a cement replacement (up to 60\% in normal strength self-compacting concrete production). The reuse of waste materials in concrete is an attempt to address a part of these problems 
Tab. 8. Hardened State Properties of SCC

\begin{tabular}{|c|c|c|c|c|c|c|}
\hline \multicolumn{2}{|c|}{ Property } & \multirow{2}{*}{$\begin{array}{l}\text { FA0 } \\
28.2\end{array}$} & \multirow{2}{*}{$\begin{array}{c}\text { FA 40 } \\
16.0\end{array}$} & \multirow{2}{*}{$\begin{array}{c}\text { FA50 } \\
10.4\end{array}$} & \multirow{2}{*}{$\begin{array}{c}\text { FA60 } \\
9.0\end{array}$} & \multirow{2}{*}{$\begin{array}{c}\text { FA 70 } \\
4.6\end{array}$} \\
\hline Unconfined & $3 d$ & & & & & \\
\hline cylinder & $7 d$ & 32.8 & 21.1 & 15.6 & 12.7 & 7.3 \\
\hline Compressive & $14 d$ & 43.4 & 22.9 & 18.5 & 17.3 & 8.3 \\
\hline Strenght & $28 d$ & 48.5 & 29.3 & 25.2 & 21.6 & 12.3 \\
\hline \multirow[t]{2}{*}{ (MPa) } & $56 \mathrm{~d}$ & 53.4 & 33.1 & 28.5 & 24.4 & 13.9 \\
\hline & $84 d$ & 58.2 & 38.1 & 33.0 & 28.5 & 16.6 \\
\hline Indirect & $14 d$ & 4.2 & 2.5 & 2.3 & 2.2 & 1.2 \\
\hline Tensile & $28 d$ & 5.1 & 3.4 & 2.8 & 2.4 & 2.1 \\
\hline Strength & $56 \mathrm{~d}$ & 5.2 & 3.7 & 3.0 & 2.8 & 2.4 \\
\hline$(\mathrm{MPa})$ & $84 d$ & 5.3 & 3.9 & 3.3 & 3.1 & 2.7 \\
\hline Immersed & $14 d$ & 7.0 & 7.1 & 7.0 & 6.8 & 7.2 \\
\hline water & $28 d$ & 6.2 & 5.3 & 5.2 & 5.5 & 6.0 \\
\hline absorption & $56 \mathrm{~d}$ & 5.4 & 3.6 & 3.2 & 3.2 & 3.8 \\
\hline$(\%)$ & $84 d$ & 4.5 & 2.3 & 1.6 & 2.8 & 3.2 \\
\hline $\begin{array}{c}\text { Apparent volume } \\
\text { of }\end{array}$ & $14 d$ & 11.5 & 11.5 & 10.9 & 11.0 & 11.1 \\
\hline $\begin{array}{c}\text { permeable voids } \\
\text { apparent }\end{array}$ & $28 d$ & 8.6 & 8.4 & 8.6 & 8.7 & 8.9 \\
\hline $\begin{array}{c}\text { volume of } \\
\text { permeable }\end{array}$ & $56 \mathrm{~d}$ & 7.8 & 5.8 & 6.1 & 6.3 & 6.6 \\
\hline voids (\%) & $84 d$ & 5.9 & 3.0 & 3.6 & 3.9 & 4.2 \\
\hline Sortivity & $14 \mathrm{~d}$ & 0.63 & 0.71 & 0.81 & 1.10 & 1.51 \\
\hline coefficent & $28 d$ & 0.54 & 0.55 & 0.72 & 0.88 & 1.36 \\
\hline \multirow[t]{2}{*}{$\left(\mathrm{kg} / \mathrm{m}^{2} h^{0.5}\right)$} & $56 \mathrm{~d}$ & 0.51 & 0.44 & 0.50 & 0.66 & 0.85 \\
\hline & $84 d$ & 0.37 & 0.30 & 0.32 & 0.41 & 0.49 \\
\hline $\begin{array}{c}\text { Chloride } \\
\text { penetration total }\end{array}$ & $24 d$ & 1954 & 1779 & 1785 & 1790 & 1783 \\
\hline $\begin{array}{l}\text { charge passed, } Q \\
\text { (coulombs) }\end{array}$ & $84 d$ & 1350 & 690 & 780 & 782 & 800 \\
\hline
\end{tabular}

by introducing sustainable materials in the construction industry and consequently reducing the carbon footprint.

\section{Conclusions}

The following conclusions can be drawn from the investigation carried out to obtain a mix proportion for medium strength SCC using low calcium fly ash and blended aggregates;

- Passing and filling ability of SCC improves with an increase in fly ash content, although passing ability remains unchanged beyond $50 \%$ cement replacement.

- Segregation resistance, in general terms, decreases with an increase in fly ash, although $40 \%$ cement replacement leads to the 'most resistant' mix.

- Mixes with $40 \%$ or more cement replaced with fly ash pass all the fresh state criteria for this study.

- Mixtures that contain fly ash have lower compressive and splitting tensile strengths, but gain strength faster in the long term. A correlation between compressive and splitting tensile strength is established for medium strength SCC with fly ash and blended aggregates.
- Cement replacement levels up to $50 \%$ produce mixes within the medium strength range (compressive strengths between $25 \mathrm{MPa}$ and $50 \mathrm{MPa})$.

- In general, apparent volume of permeable voids and water absorption rates decrease with curing age. However significant differences between fly ash and the control mix only occur after 56 days. apparent volume of permeable voids and the water absorption rate start increasing again beyond $40 \%$ and $50 \%$ replacement respectively.

- Sorptivity increases significantly beyond $30 \%$ replacement, although mixes with $40 \%$ and $50 \%$ fly ash still show acceptable sorptivity.

- Fly ash improves resistance to chloride ion penetration significantly while further improvement with time (at 84 days) is also achievable for fly ash containing mixes.

- The recommended mix proportion for the production of medium strength SCC with blended aggregates for normal applications, as per this study, is $40 \%$ fly ash replacement.

\section{References}

1 Skarendahl A, Petersson O (eds.), Self compacting concrete State-of-theart report of RILEM technical committee 174-SCC, RILEM Publications S.A.R.L.; France, 2000. Report RILEM TC 174 SCC, 
2 Khayat KH, Workability, Testing, and Performance of Self-Consolidating, ACI Materials Journal, 96, (1999), 346-354.

3 Sambasivan M, Soon YW, Causes and effects of delays in Malaysian construction industry, International Journal Project Management, 25, (2007), 517-526, DOI 10.1016/j.ijproman.2006.11.007

4 Vilanova A, Fernandez-Gomez J, Landsberge GA, Evaluation of the mechanical properties of self compacting concrete using current estimating models: Estimating the modulus of elasticity, tensile strength, and modulus of rupture of self compacting concrete, Construction and Building Materials, 25, (2011), 3417-3426, DOI 10.1016/j.conbuildmat.2011.03.033

5 Nagaratnam BH, Rahman ME, Mannan MA, Faheem A, Investigation on Workability of SCC Using Low Calcium Based Fly ash, Proceedings 3rd CUTSE International Conference, In:; Sarawak, Malaysia, 2011-11-08.

6 Nagaratnam BH, Rahman ME, Mannan MA, A Study on Hardened State Properties of SCC using Fly Ash and Blended Fine Aggregates, Advanced Material Research, 622, (2013), 1789-1793, DOI 10.4028/www.scientific.net/AMR.622-623.1789

7 European Committee for Standardization, Aggregates for concrete, 2013. Standard: EN 12620.

8 American Society for Testing and Materials, Standard Specification for Concrete Aggregates, 2013. Standard: ASTM C33.

9 European Committee for Standardization, Cement - Part 1: Composition, specifications and conformity criteria for common cements, 2011. Standard: EN 197-1.

10 American Society for Testing and Materials, Standard Specification for Coal Fly Ash and Raw or Calcined Natural Pozzolan for use in Concrete, 2013. Standard: ASTM C618 - 12a.

11 European Committee for Standardization, Admixtures for concrete, mortar and grout Concrete admixtures. Definitions, requirements, conformity, marking and labelling, 2012. Standard: EN 934-2.

12 Specification and guidelines for self-compacting concrete, EFNARC; UK, 2002.

13 The European guidelines for self-compacting concrete, BIBM, CEMBUREAU, ERMCO, EFCA, EFNARC, 2005.

14 Guidelines for testing fresh self-compacting concrete: TESTING SCC, 2005.

15 TR-6-03: Interim Guidelines for the Use of Self-Consolidating Concrete in Precast/Prestressed Concrete Institute Member Plants, Precast/Prestressed Concrete Institute; USA, 2003.

16 European Committee for Standardization, Testing hardened concrete Compressive strength of test specimens, 2009. Standard: EN 12390-3.

17 European Committee for Standardization, Testing hardened concrete Tensile splitting strength of test specimens, 2009. Standard: EN 12390-6.

18 American Society for Testing and Materials, Standard Test Method for Density, Absorption, and Voids in Hardened Concrete, 2013. Standard: ASTM C642-13.

19 American Society for Testing and Materials, Standard Test Method for Measurement of Rate of Absorption of Water by Hydraulic-Cement Concretes, 2013. Standard: ASTM C1585-13.

20 American Society for Testing and Materials, Standard Test Method for Electrical Indication of Concrete's Ability to Resist Chloride Ion Penetration, 2012. Standard: ASTM C1202-12.

21 Bouzoubaa N, Lachemi M, Self-compacting concrete with different levels of pulverised fuel ash, Construction and Building Materials, 31, (2010), 413420.

22 Pathak N, Siddique R, Properties of self compacting concrete containing fly ash subjected to elevated temperatures, Construction and Building Materials, 30, (2012), 274-280, DOI 10.1016/j.conbuildmat.2011.11.010

23 Brouwers HJH, Radix HJ, Self-Compacting Concrete: Theoretical and experimental study, Cement and Concrete Research, 35, (2005), 2116-2136, DOI $10.1016 /$ j.cemconres.2005.06.002

24 Liu M, Self-compacting concrete with different levels of pulverized fuel ash, Construction and Building Materials, 24, (2010), 1245-1252, DOI 10.1016/j.conbuildmat.2009.12.012

25 Benabed B, Kadri EH, Azzouz L, Kenai S, Properties of self-compacting mortar made with various types of sand, Cement and Concrete Composites, 34, (2012), 1167-1173, DOI 10.1016/j.cemconcomp.2012.07.007

26 Sonebi M, Medium strength self-compacting concrete containing fly ash: Modelling using factorial experimental plans, Cement and Concrete Research, 34, (2003), 1199-1208.

27 Khatib JM, Performance of self-compacting concrete containing fly ash, Construction and Building Materials, 22, (2006), 1963-1971, DOI 10.1016/j.conbuildmat.2007.07.011

28 Malhotra VM, High-Performance High-Volume Fly Ash Concrete, Proceedings of the International Conference on HPHSC, In:; Australia, 1998, pp. 97122.

29 Sukumar B, Nagamani K, Srinivasa RR, Evaluation of strength at early ages of self-compacting concrete with high volume fly ash, Construction and Building Materials, 22, (2008), 1394-1401, DOI 10.1016/j.conbuildmat.2007.04.005

30 Siddique R, Properties of self-compacting concrete containing class F fly ash, Materials and Design, 32, (2011), 1501-1507, DOI 10.1016/j.matdes.2010.08.043

31 Warner RF, Rangan BV, Hall AS, Faulkes KA, Concrete Structures, Addison Wesley Longman Australia Pty Limited; Australia, 1998, ISBN ISBN 0-582-80247-4.

32 Kosmatka SH, Kerkhoff B, Panarese WC, Design and control of concrete mixtures: 14th Ed, Portland Cement Association; Illinois, USA, 2002, ISBN ISBN 978-0893122171.

33 Neville AM, Properties of concrete: 4th Ed, CTP-VVP; Malaysia, 1996, ISBN 0470235276.

34 Holschemacher K, Klug Y, A database for the evaluation of the hardened properties of SCC, LACER, 7, (2002), 124-134.

35 Dinakar P, Babu KG, Santhanam M, Durability properties of high volume fly ash self compacting concretes, Cement and Concrete Composites, 30, (2008), 880-886, DOI 10.1016/j.cemconcomp.2008.06.011

36 Kao G, Water absorption, water permeability, $\mathcal{E}$ RTA sorptivity test on Xypex admix c-series (C-1000nf) modified commercial concretes, The Australian Centre for Construction Innovation, UNSW, Xypex Australia, 2004, http: //www. xypex.com.au/file/2428/370

37 Marsh B, High volume fly ash concrete, Concrete, 37, (2003), 54-55.

38 Naik TR, Singh SS, Hossain MM, Properties of high performance concrete systems incorporating large amounts of high-lime fly ash, Construction and Building Materials, 9, (1995), 195-204, DOI 10.1016/09500618(95)00009-5

39 Koehler EP, Fowler DW, Aggregates in self-consolidating concrete, AFTRE, ICAR, The University of Texas at Austin; America, 2007. Research report ICAR 108-2f.

40 Patel R, Hossain KMA, Shhata M, Bouzabaa N, Lachemi M, Development of statistical models for mixture design of high-volume fly ash selfconsolidation concrete, ACI Material Journal, 101, (2004), 294-302.

41 Uysal M, Yilmaz K, Effect of mineral admixtures on properties of selfcompacting concrete, Cement and Concrete Composites, 33, (2011), 771776, DOI 10.1016/j.cemconcomp.2011.04.005

42 Fredrik B, Concrete Technology and Sustainable Development, Symposium on Concrete Technology for Sustainable Development, In:; Vancouver, Canada, 1999.

43 Juan C, Breixo G, Juan LD, Salvador GM, Hortensia GL, Calculation of the corporate carbon footprint of the cement industry by the application of MC3 methodology, Ecological Indicators, 11, (2011), 1526-1540, DOI 10.1016/j.ecolind.2011.02.013 